\title{
EFFECTS OF DIET'S ACIDIFYING ADDITIVES ON THE INTESTINAL HISTOMORPHOLOGY IN DUCKS
}

\author{
Ahmed Abdelfattah-Hassan*, Hanaa M. El-Ghazali
}

Department of Anatomy and Embryology, Faculty of Veterinary Medicine, Zagazig University, 44519, Egypt

*Corresponding author, E-mail: aabdelfattah@vet.zu.edu.eg

\begin{abstract}
This study aimed at evaluating the effect of acidifying additives as formic and propionic acids on weight gain and on small intestinal macroscopic, microscopic and SEM morphology in ducks. A total of 30 Mulard ducklings were used in this study and they were randomly assigned to control (given standard commercial duck diets with no acidifiers added), $1 \%$ acidifiers added to the standard diet or $2 \%$ acidifiers added to the standard diet. After rearing the ducks for 52 days, their weight was recorded and then the length of the different parts of the small intestine was measured. Then, samples were taken for histological and scanning electron microscopical (SEM) examination of the small intestine. The present results found that addition of acidifying mixture to the diet significantly improved duck's weight $(P<0.05)$, also there were significant changes in length, histology and SEM characteristics of the small intestine between different duck groups. The observed effects were dose dependent, i.e. with more organic acids in the diet, the more the changes were noticeable. Our results indicate that, the addition of organic acids to duck's diet increased small intestine's length and increased the length of intestinal villi, possibly resulting in more surface area for digestion and absorption of the diet, and, therefore, greatly improved the final body weight of the study ducks.
\end{abstract}

Key words: acidified diets; organic acids; histology; intestinal villi; SEM

\section{Introduction}

Poultry meat is a good source of proteins and other valuable nutrients for human consumption, and it is considered an essential supply to meet the growing human population. The unsupervised use of antibiotics in poultry industry is still a serious problem and it poses great risks to human health; when improperly used as growth promotors. Antibiotics use as growth promotors is illegal now in Europe, since the European Union has banned their use in 2006.
Other alternatives are currently still being studied in poultry industry and one modern feeding strategy is changing the $\mathrm{pH}$ of the diet through addition of acidifying substances; as organic acids. These acids will slightly change the $\mathrm{pH}$ of the intestine, and also has direct antibacterial effects (1-3). So, it will reduce the intestinal bacterial load, improve production and eliminate the need for antibiotics use as growth promotors. Several commercial mixtures of organic acids and inorganic acids are currently in 
the market in the European Union as better replacements to growth promoting antibiotics.

Being acids, organic acids improve the digestibility of dietary proteins and amino acids in the stomach, by enhancing the digestion of proteins (4). In addition, they improve the utilization of feed and result in better feed conversion and growth rates. Moreover, an additional advantage of organic acids is their use in the preservation of broiler feed stuff (5). Therefore, the addition of organic acids to the feed ingredients preserves its properties for longer time, result in better growth in reared poultry and increase the profitability for poultry producers.

In fact, the addition of acidifying substances was described previously in poultry; to control infections such as campylobacter or to improve the weight gain of reared poultry. Several acids were used, such as, lactic acid in the drinking water (1), organic acids in drinking water (6), formic acid in feed (7) along with other additives reviewed in (8). Their use resulted in improved weight gain in poultry, because these organic acids enhance diet's protein and energy use and reduce microbial competition for these nutrients in bird's intestine (reviewed in (3)). Moreover, the addition of these acidifying substances was not harmful and did not cause damage in the intestinal epithelium, on the contrary it increased chicken-flock's biosecurity and prevented infections that could be harmful to human consumers $(6,9)$. In humans, dietary additives or high fat diets were also described to change intestinal adaptation and enhanced the growth of the intestinal villi after removal of parts of the bowl in resection operations (10), and it could be a useful strategy in treating humans with short gut syndrome (11-13).

The possible macroscopic and microscopic changes to the intestine and intestinal villi upon feeding acidified diets has not been studied in detail in ducks. Therefore, the present study aimed at studying the small intestine's morphology, histology and scanning electron microscopy in response to feeding acidified diets (through addition of organic acids to the standard diet) in ducks.

\section{Material and methods}

All procedures in the study were following animal care and use committee of the Faculty of Veterinary Medicine, Zagazig University.

\section{Birds and study design}

Mulard Ducklings $(\mathrm{n}=30)$; a sterile breed of domestic ducks raised for meat production and is a hybrid between male Muscovy (Cairina moschata) and female Pekin (Anas platyrhynchos domestica) ducks, were purchased from a commercial duck hatchery. Upon arrival, the ducklings were weighed and randomly assigned to one of three groups (each group contained 10 ducklings) and reared for 52 days in Bird Nutrition Research Unit (Nutrition and Clinical Nutrition Department, Faculty of Veterinary Medicine, Zagazig University).

Ducklings feeding program consisted of standard starter diet (up to 21 days) and finisher diet (22-52 days). A commercial acidifier mixture was purchased, and it contained mainly formic acid and propionic acid. The three study groups received no (Control), $1 \%$ acidifier mixture in diet (1AM) or $2 \%$ acidifier mixture in $\operatorname{diet}(2 \mathrm{AM})$. No forced feeding was done in this study and ducks had free access to water. After completing the rearing period, all ducks were weighed and then slaughtered, and samples were taken immediately.

\section{Gross anatomical examination}

Directly after slaughtering the study ducks, the intestine was removed and visually inspected for any apparent differences, then carefully straightened so the length of each small intestine segment (duodenum, jejunum and ileum) was easily measured. Duodenum was defined starting from its beginning after the gizzard (ventriculus) till the beginning of the mesojejunum (the jejunal mesentery), the jejunum was measured from the end of the duodenum till the end of the mesojejunum, while the ileum was measured from the end of the mesojejunum till the junction between the ileum and the two ceca. Also, the length of the two ceca (part of the large intestine) was recorded. 


\section{Histological examination}

After performing the anatomical examination, samples from the middle of each part of the small intestine was taken, emptied from its contents by flushing with warm physiological saline solution and, then, immediately fixed in freshly prepared $10 \%$ neutral buffered formalin solution for at least 48 hours. Care was taken to obtain the samples from the same region in all study ducks. Afterwards, standard histological procedure was performed (dehydration in ascending grades of alcohol, clearing in xylene and embedding in paraffin wax). Finally, $5 \mu \mathrm{m}$ sections were obtained, mounted, stained with Hematoxylin and Eosin stain (H\&E) and examined under light microscopy.

The general structure (mucosa, submucosa and muscular layer) of each part of the small intestine was examined and the height (including the crypt of Lieberkühn) and width of the intestinal villi, and the thickness of the muscularis mucosa were measured using S-view computer software provided with the microscope camera (EHC10, S-VIEW Technology Co., Ltd, Zhejiang, China).

\section{Scanning Electron Microscopy}

For the Scanning Electron Microscopy (SEM), a two cm long intestine sample (from the part next to the samples obtained for histological examination) was cut open longitudinally, the cut was made very carefully not to touch the intestinal mucosa, and the mucosa was washed again with warm phosphate buffered saline. The SEM procedure followed previously published protocols for birds $(14,15)$. Briefly, the samples were immersed in $3 \%$ glutaraldehyde (in $0.1 \mathrm{M}$ cacodylate buffer, $\mathrm{pH} 7.4$ ) at room temperature and transported to the SEM unit (Al-Azhar University, Cairo, Egypt). Then, the samples were cut into smaller pieces (approx. $5 \mathrm{~mm}^{2}$ ) with sharp razor blades and fixed for an additional one hour in the same buffer. Then, the pieces were washed with $0.1 \mathrm{M}$ sodium cacodylate buffer ( $\mathrm{pH} 7.4)$ and postfixed with $1 \%$ osmium tetroxide (in ice-cold $0.1 \mathrm{M}$ sodium cacodylate buffer, $\mathrm{pH} 7.4$ ) for two hours. Afterwards, the samples were washed with pure distilled water and dehydrated in ascending concentration of ethanol $(50 \%$ to $100 \%, 2$ times in each concentration for at least 20 min each). following this, the samples were critical point dried using liquid carbon dioxide (Autosamdri ${ }^{\circledR}-815$, Tousimis, Maryland, USA), mounted on aluminum stubs with electrically conducting carbon mounting tabs and finally sputter-coated (SPI-Module ${ }^{\mathrm{TM}}$ Sputter Coater, Pennsylvania, USA). The arrangement of the villi and their surface epithelium were observed using JOEL scanning electron microscope (JSM-5500LV, JEOL Ltd., Tokyo, Japan) at $17-20 \mathrm{kV}$ accelerating voltage.

\section{Statistical analyses}

The data collected was evaluated using ANOVA procedure, post hoc comparisons were applied, whenever appropriate, using Tukey's HSD test. All statistical procedures were performed using PASW statistics v.18 (SPSS Inc., USA). Statistical significance was considered at $\mathrm{P} \leq 0.05$.

\section{Results}

Effects of acidifying mixtures on duck's final body weight

The addition of acidifying mixture to duck's diet (starter and finisher), greatly improved the final body weight of the ducks during the 52 days study period $(\mathrm{P}<0.05$, Table 1$)$. With highest duck's weight obtained in the group supplied with $2 \%$ organic acids, followed by $1 \%$ organic acids, and the least weight belonged to duck's that did not have organic acids in their diets.

\section{Gross anatomical findings}

After measuring the length of the different parts of the small intestine (duodenum, jejunum and ileum), the addition of acidifying mixtures ( $1 \%$ or $2 \%)$ resulted in longer duodenum, jejunum, ileum and ceca compared to the control group with no additives $(\mathrm{P}<0.05$, Table 1$)$. In addition, only in the ileum, the $2 \%$ acids mixture resulted in significant longer intestinal length than in the $1 \%$ group $(\mathrm{P}<0.05)$. 


\section{Histological findings}

The addition of organic acids to the duck's diet resulted in significantly different length of duodenal, jejunal and ileal villi $(\mathrm{P}<0.05$, Table 1). The shape and arrangement of the intestinal villi in duodenum, jejunum and ileum were also microscopically changed at $40 \mathrm{X}$ (Plate 1). At higher magnifications (100X, plate 1 , and 400X, not shown) there were no observable difference in the lamina propria or the Crypts of
Lieberkühn with H\&E stain. The addition of organic acids to the diet increased villus length $(\mathrm{P}<0.05)$ and the villi were less wide than in ducks fed no organic acids in their diets. The longest and thinnest duodenal villi were observed in the $1 \%$ group, while the longest and thinnest jejunal and ileal villi were observed in the $2 \%$ group (Table 1). The intervillous space was similar in duodenum in all groups, and it was wider in the $1 \%$ and $2 \%$ groups compared to the control group with no additives in their diet (Plate 1, Figs. H, K, I, L, N, Q, O and R).

Table 1: Showing the final body weight, length of different parts of the small intestine (including villus length, width and muscularis thickness) and length of the ceca of studied Mulard ducks given no (control), $1 \%$ organic acids or $2 \%$ organic acids in their diets

\begin{tabular}{|c|c|c|c|}
\hline & Control & $\begin{array}{c}1 \% \text { organic acids in } \\
\text { diet }\end{array}$ & $\begin{array}{c}2 \% \text { organic acids in } \\
\text { diet }\end{array}$ \\
\hline Final body weight (gm) & $2407 \pm 96.21^{\mathrm{c}}$ & $2690 \pm 84.23^{b}$ & $2895 \pm 93.39^{\mathrm{a}}$ \\
\hline Duodenum length (cm) & $29 \pm 2.58^{\mathrm{b}}$ & $33.33 \pm 2.17^{\mathrm{a}}$ & $34.67 \pm 2.26^{\mathrm{a}}$ \\
\hline Jejunum length $(\mathrm{cm})$ & $98.33 \pm 5.89^{\mathrm{b}}$ & $112.33 \pm 6.38^{\mathrm{a}}$ & $116.33 \pm 8.71^{\mathrm{a}}$ \\
\hline Ileum length $(\mathrm{cm})$ & $22.33 \pm 3.20^{\mathrm{c}}$ & $26.67 \pm 4.36^{\mathrm{b}}$ & $30.33 \pm 5.21^{\mathrm{a}}$ \\
\hline Cecum length $(\mathrm{cm})$ & $9.67 \pm 1.45^{b}$ & $12.67 \pm 1.33^{\mathrm{a}}$ & $13.33 \pm 1.67^{\mathrm{a}}$ \\
\hline Duodenum villus height ( $\mu \mathrm{m})$ & $1184.33 \pm 98.52^{b}$ & $1613.00 \pm 131.55^{\mathrm{a}}$ & $1579.75 \pm 82.45^{\text {a }}$ \\
\hline Jejunum villus height $(\mu \mathrm{m})$ & $883.00 \pm 84.21^{\mathrm{c}}$ & $863.25 \pm 110.98^{b}$ & $901.00 \pm 174.27^{\mathrm{a}}$ \\
\hline Ileum villus height $(\mu \mathrm{m})$ & $393.00 \pm 40.05^{\mathrm{c}}$ & $671.88 \pm 107.03^{b}$ & $797.43 \pm 97.03^{\mathrm{a}}$ \\
\hline Duodenum villus width $(\mu \mathrm{m})$ & $145.00 \pm 15.89^{\mathrm{a}}$ & $116.89 \pm 39.68^{\mathrm{c}}$ & $134.83 \pm 16.52^{b}$ \\
\hline Jejunum villus width $(\mu \mathrm{m})$ & $225.44 \pm 49.02^{a}$ & $206.00 \pm 38.05^{b}$ & $171.67 \pm 16.50^{c}$ \\
\hline Ileum villus width $(\mu \mathrm{m})$ & $176.00 \pm 18.69^{\mathrm{a}}$ & $162.00 \pm 16.81^{\mathrm{b}}$ & $143.71 \pm 21.41^{\mathrm{c}}$ \\
\hline Duodenum muscularis thickness $(\mu \mathrm{m})$ & $469.67 \pm 91.31^{\mathrm{a}}$ & $419.80 \pm 32.91^{b}$ & $373.83 \pm 75.77^{\mathrm{c}}$ \\
\hline Jejunum muscularis thickness $(\mu \mathrm{m})$ & $319.50 \pm 58.52^{b}$ & $347.67 \pm 54.38^{\mathrm{a}}$ & $364.00 \pm 46.25^{\mathrm{a}}$ \\
\hline Ileum muscularis thickness $(\mu \mathrm{m})$ & $233.50 \pm 25.32^{b}$ & $254.33 \pm 28.08^{\mathrm{a}}$ & $258.33 \pm 39.55^{\mathrm{a}}$ \\
\hline
\end{tabular}

Different superscript letters denote statistical significance $(\mathrm{P}<0.05)$. Values shown as mean \pm standard deviation 
Scanning Electron Microscopical findings

Results of the scanning electron microscopy showed the differences in shape and arrangement of the villi in different parts of the duck's small intestine in response to acidified diets (shown in Plates 2, 3, 4). Compared to the control group the duodenal villi were thinner, more abundant and interwoven between each other in the $1 \%$ group (Plate 2, Fig. D). While, in the 2\% group they appeared thin, taller and less abundant (Plate 2, Fig. G). At higher magnifications (800X and 1500X) there were no obvious differences in the surface at the tip or sides of the duodenal villi between the study groups (Plate 2, Figs. B, C, E, F, H, I). In case of the jejunum, differences were more difficult to be noticed with the SEM (Plate 3). Only the sides of jejunal villi in the $2 \%$ group showed corrugations (Plate 3, Fig. H), these were less prominent in the $1 \%$ group and difficult to be observed in the control group. Differences in the ileum, between groups, were more pronounced than in the duodenum or jejunum. The $2 \%$ group showed more numerous ileal villi which are thinner and intermingled (Plate 4, Fig. G) with fairly corrugated sides at higher magnification (Plate 4, Fig. H). Whereas in the $1 \%$ group the ileal villi appeared less numerous than the $2 \%$ group and showed corrugated sides at higher magnification (Plate 4, Figs. D \& E). At higher magnification $(>1500 \mathrm{X})$ the surface of the ileal villi in different groups showed no obvious differences (Plate 4, Figs. C, F, I).
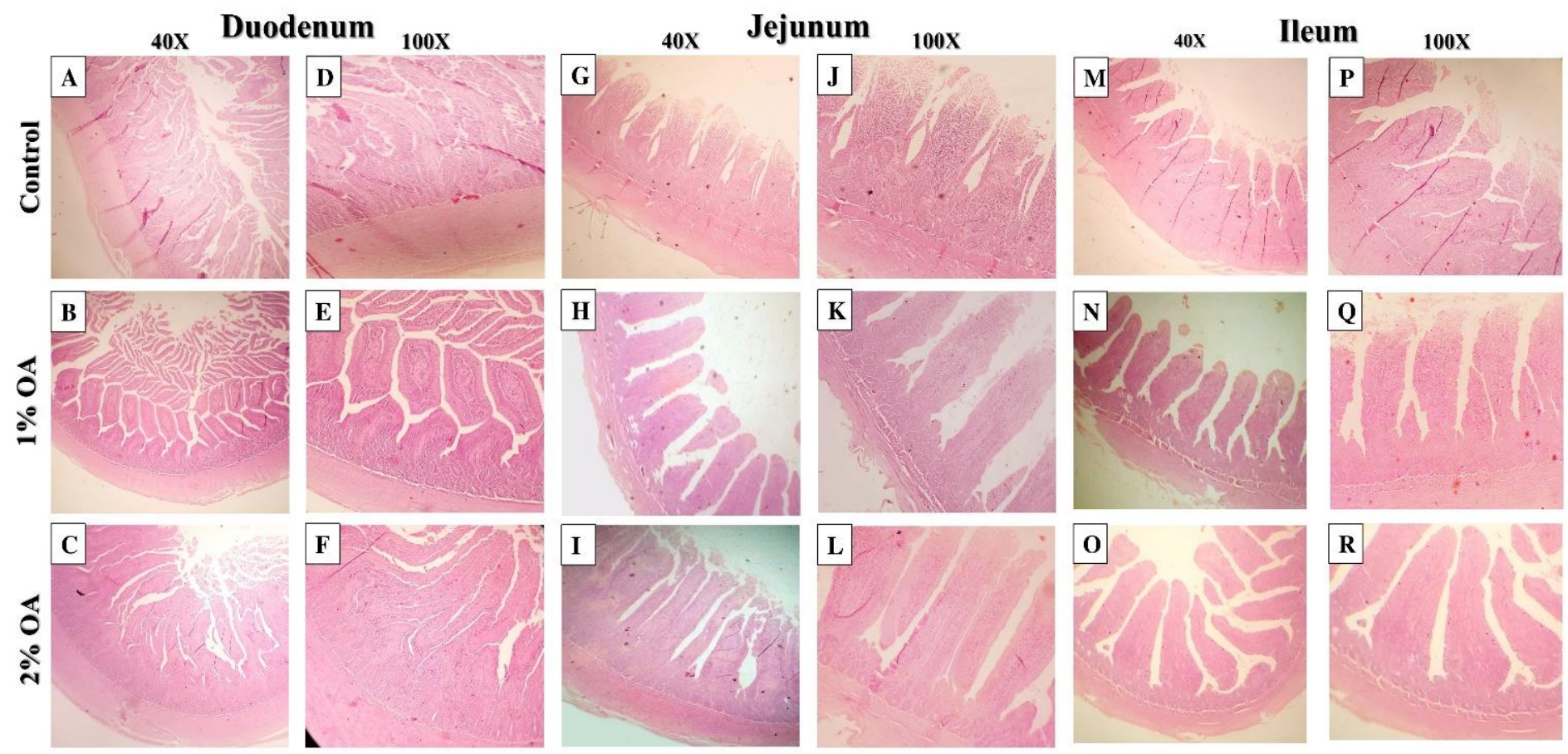

Plate 1: Photomicrographs A-R, showing the H\&E sections of duodenum, jejunum and ileum in the study groups given no (Control), $1 \%$ organic acids (1\% OA) or $2 \%$ organic acids $(2 \% \mathrm{OA})$ in their diet for 52 days. Different length and arrangement of intestinal villi were noticed in response to the organic acids' administration is evident at $40 \mathrm{X}$ and $100 \mathrm{X}$ magnification 


\section{Discussion}

Knowledge on duck's intestinal macro and microscopic anatomy is much less than the chicken in the literature, so far it has been given less attention. The histochemical developmental changes of the small intestine in ducks was described for the first time in 2011 (16). We here showed normal macroscopic and microscopic anatomy of the adult duck's small intestine, and possible changes that could arise from using modern feed additives; such as organic acids.

The present results showed that with changing the acidity of the diet, by incorporation of organic acids, the ducks weight improved (Table 1) while their feed intake was not changed significantly (data not shown). Similar improvements were detected in Aigamo ducks fed bamboo charcoal with vinegar (17) or natural zeolite including plant extract (18), in chicken fed organic acids (4) and pigs fed organic acids, reviewed in (19). Whilst, some studies in broiler chickens didn't find changes in final body weight; mainly because feed intake was not calculated and no normalization of bird's weight to its feed intake was done (6) or due to the use of single organic acid at a much lower concentration in the diet (7).

No damage was observed in the epithelium of the villi by SEM, nor visual differences was found, this underlines the safety of using up to $2 \%$ organic acids in the diet of ducks without causing any adverse effects. In chicken, organic acids use was also found to be safe on the intestine and did not cause damage to the villi (6).
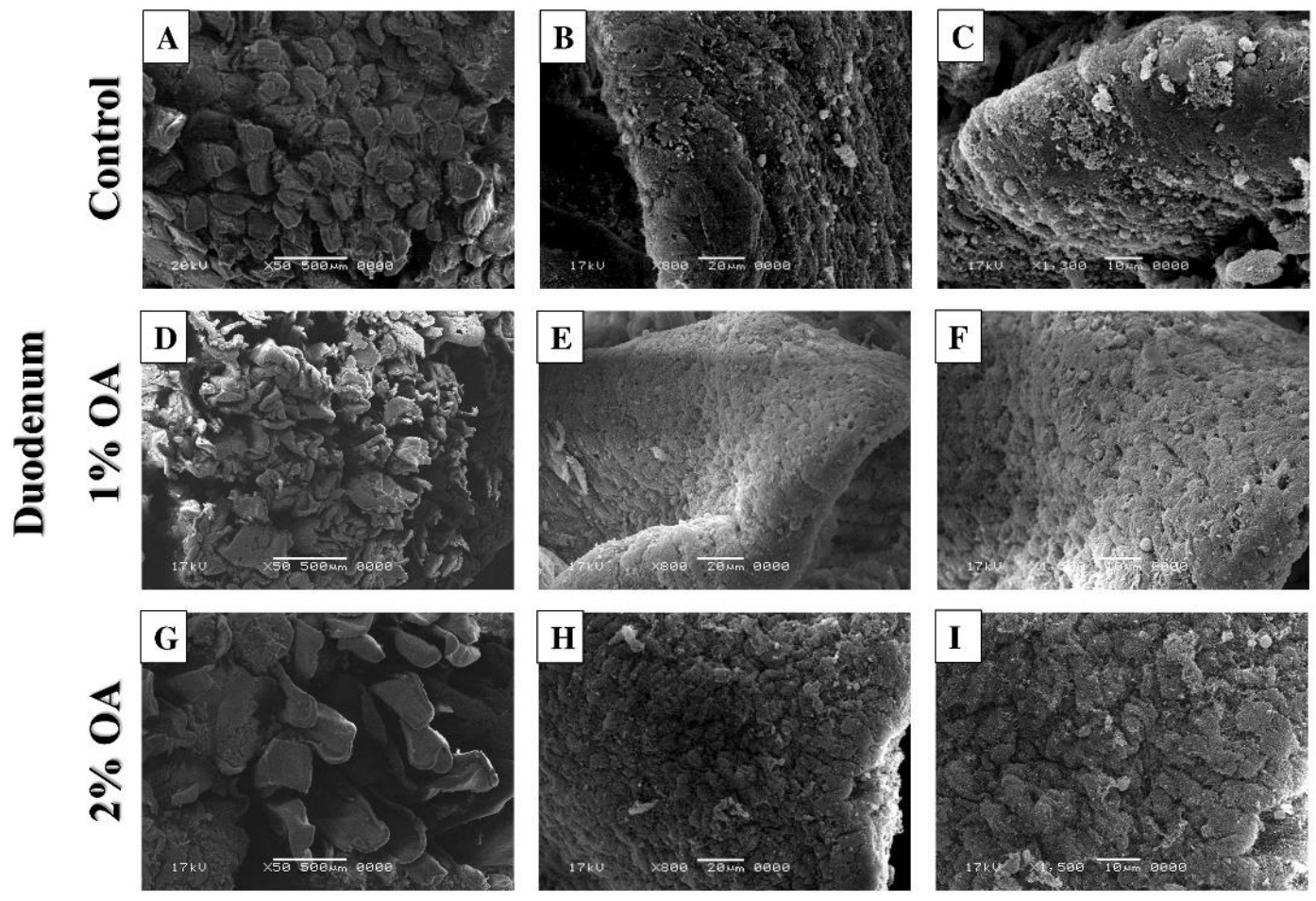

Plate 2: Photomicrographs A-I, showing the SEM scans of duodenum in the study groups given no (Control), $1 \%$ organic acids (1\% OA) or $2 \%$ organic acids (2\% OA) in their diet for 52 days. Different arrangement of intestinal villi was noticed in response to the organic acids' administration were noticed 

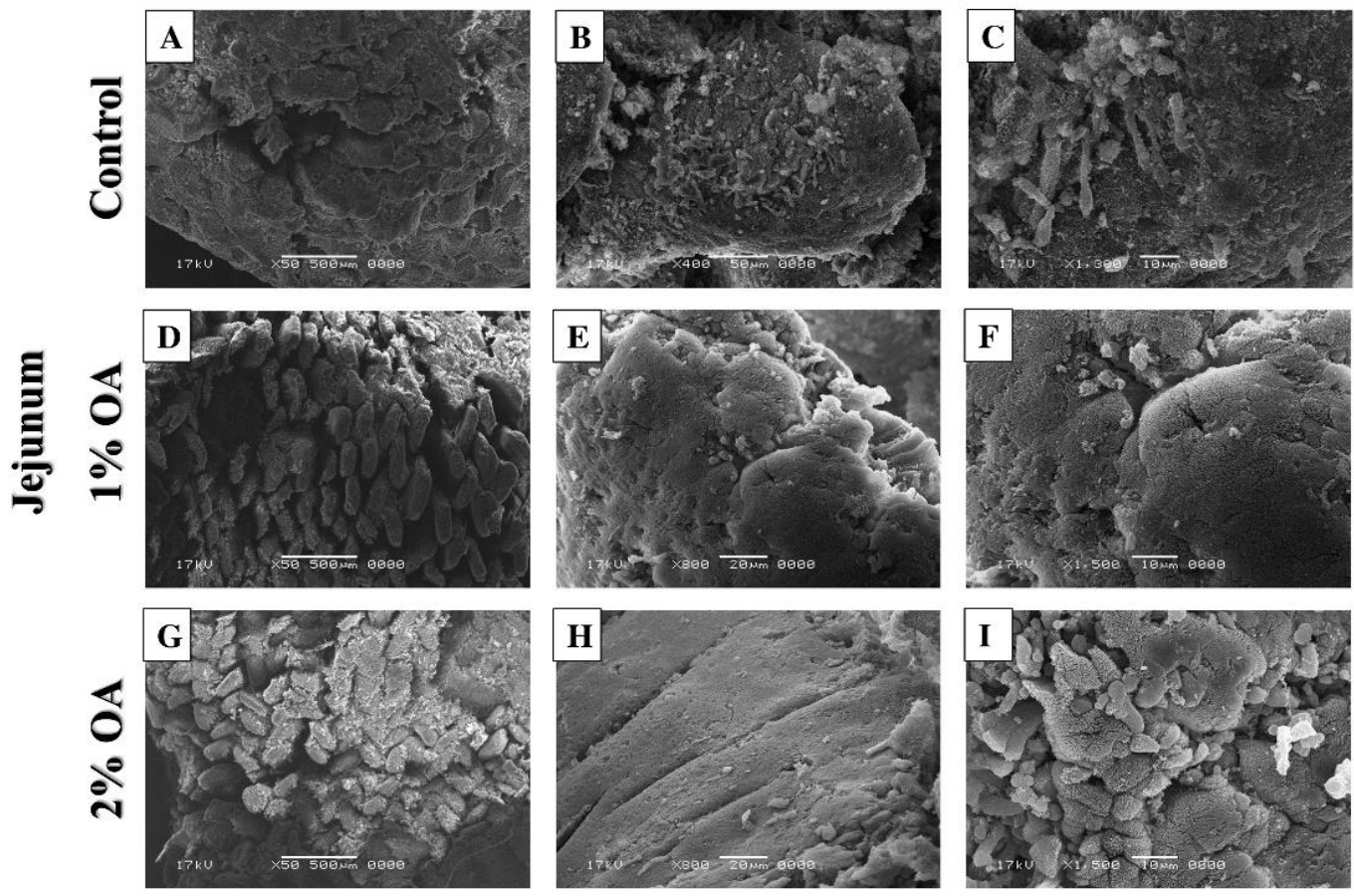

Plate 3: Photomicrographs A-I, showing the SEM scans of jejunum in the study groups given no (Control), $1 \%$ organic acids $(1 \% \mathrm{OA})$ or $2 \%$ organic acids $(2 \% \mathrm{OA})$ in their diet for 52 days. Different arrangement of intestinal villi was noticed in response to the organic acids' administration were noticed
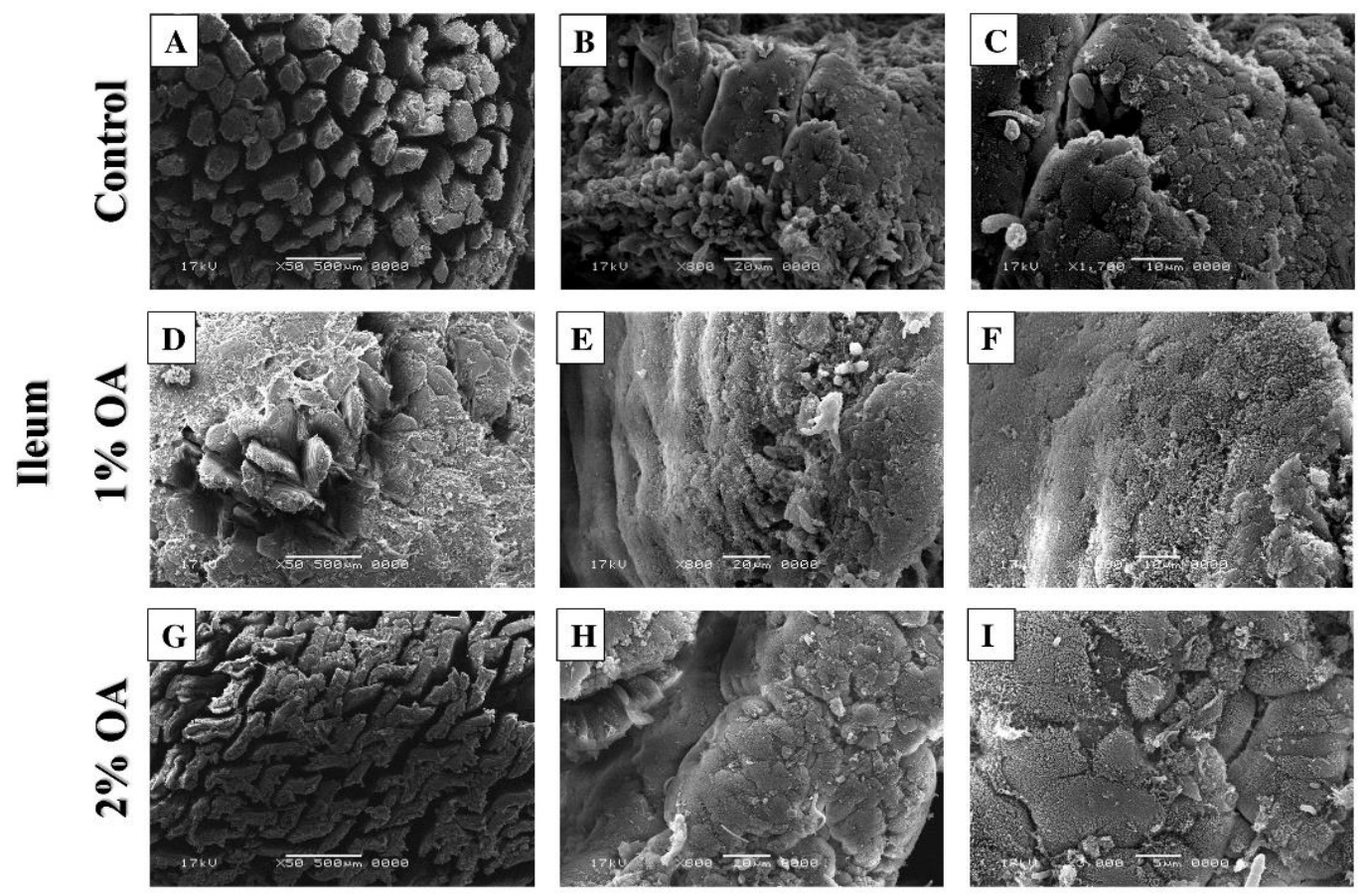

Plate 4: Photomicrographs A-I, showing the SEM scans of ileum in the study groups given no (Control), $1 \%$ organic acids ( $1 \% \mathrm{OA})$ or $2 \%$ organic acids (2\% OA) in their diet for 52 days. Different arrangement of intestinal villi was noticed in response to the organic acids' administration were noticed 
The length of the intestine in ducks, and poultry in general, is directly proportional to the absorption and utilization of digested feed (20). Consequently, our results showed that by adding organic acids in duck's diet, longer intestine with longer villi were obtained which resulted in substantially increasing the surface area of absorption, and therefore, increased feed utilization with achieving higher final body weight. Longer intestinal villi with organic acids administration were also recently reported in broiler chickens (4).

The ileum in poultry; ducks is no exception, has a characteristic ileal digestion (21), it was described to increase with addition of a single organic acid to the diet (7). The current results showed longer ileum and ileal villi with more organic acids in the diet, which implies that the utilization of feed is at its maximum, and this was reflected on the weight of reared ducks; as observed in our $2 \%$ organic acids group compared to the other groups. In addition, a higher dose of organic acids ensures that their favorable effects reach to the jejunum and ileum, thus guaranteeing maximum benefit from its actions throughout most of the small intestine; similar observations were previously reported in pigs (19).

From our results, the $2 \%$ group ducks had the highest final body weight and this group had longer duodenum, jejunum and ileum, also with longer villi, than the remaining groups. Although, it is difficult in this study to clearly determine whether the body weight was increased due to longer intestinal parts or the longer intestinal parts are a consequence to higher body weight, either ways the result is higher duck's weight and thus profitability in duck farming. In the $1 \%$ group these findings were also present but to a lower extent compared to the $2 \%$ group. This also highlights that the observed weight improvement and histomorphological changes in this study are dose dependent.

The arrangement of the villi was also different between groups with addition of organic acids to the diet. In the duodenum the villi became interwoven or zigzag-like and it was difficult to obtain a single straight villus in the H\&E section (Plate 1, Figs. B \& E) this was very clear with the $1 \%$ group and less clear in the $2 \%$ group compared to control ducks. While in the SEM the $2 \%$ group showed zigzag arrangement of jejunal villi (Plate 3, Fig. G). This could mean that different concentrations of organic acids can change the intestinal morphology. This interwoven or zigzag pattern of villus arrangement was mentioned in broiler chickens after giving organic acids in their diet (4); however, the authors failed to show any pictures of such arrangement in the published paper. The interwoven or zigzag arrangement of intestinal villi reported in the present study and in others suggests a more efficient nutrient absorption; as nutrients will have more contact time with the intestinal villi epithelium (22). Possible explanation to these changes in the arrangement of the villi could be due to either increased villus length (as seen in the present H\&E results) or changes in the number of villi per square $\mathrm{cm}$ of intestine (as seen in the present SEM results). This was evident in both H\&E stained sections and SEM images of the different intestinal parts; however, the exact mechanism needs further investigation.

It has been previously noticed that the intestinal villi shape and length changed in response to feed additives. For example, changes in villus height and cell mitosis rate was seen in response to dietary bamboo charcoal with vinegar (17) and to dietary natural zeolite including plant extract (18) in Aigamo ducks. Also, similar intestinal villi changes were seen in broiler chickens in response to addition of formic acid $(7,23)$, organic acid salts (24), organic acids (4) and aflatoxins (25) in their diet. In addition, similar differences were observed by comparing village chickens to commercial broilers in Malaysia (26).

Finally, from the previous studies and our results, one can hypothesize that any changes or even small amounts of additives to bird's diet can greatly alter the intestinal length and villus morphology. An important question could arise from this point, as changing a single constituent of the diet (addition of organic acids or simply changing the $\mathrm{pH}$ of the diet) caused changes in intestine's anatomy, histology and SEM within the same animal species. Therefore, could the 
anatomical differences in the digestive system (macro and microscopic anatomy) between different species of birds be attributed to its feed habits rather than species-related differences? Answers to this question are unavailable in the literature and this needs further investigation.

\section{Conclusions}

The present results indicate that the addition of up to $2 \%$ organic acids to duck's diet increased small intestine's length and increased the length of intestinal villi without adverse effects on their microscopic structure. This evidently led to larger surface area for digestion and absorption of the feed, and, therefore, greatly improved the final body weight of the study ducks. It is, therefore, recommended to use $2 \%$ organic acids in duck's diet.

\section{Conflict of interest}

The authors declare no conflict of interest.

\section{Acknowledgments}

This work was funded by personal funds from the present authors. We would like to thank Ass. Prof. Dr. Doaa Ibrahim Mohammed at the Bird Nutrition Research Unit (Nutrition and Clinical Nutrition Department, Faculty of Veterinary Medicine, Zagazig University) for help with feeding and rearing the study ducks.

\section{Supplementary data}

Supplementary data is available upon reasonable request by e-mailing the corresponding author. The file contains detailed methodology used herein in addition to supplementary plates and tables.

\section{References}

1. Byrd JA, Hargis BM, Caldwell DJ, Bailey RH, Herron KL, McReynolds JL, Brewer RL, Anderson RC, Bischoff KM, Callaway TR, Kubena LF. Effect of lactic acid administration in the drinking water during preslaughter feed withdrawal on Salmonella and Campylobacter contamination of broilers. Poultry Science. 2001; 80:278-83.

2. Chaveerach P, Keuzenkamp DA, Urlings HA, Lipman LJ, van Knapen F. In vitro study on the effect of organic acids on Campylobacter jejuni/coli populations in mixtures of water and feed. Poultry Science. 2002; 81:621-28.
3. Dibner JJ, Buttin P. Use of organic acids as a model to study the impact of gut microflora on nutrition and metabolism. Journal of Applied Poultry Research. 2002; 11:453-63.

4. Samanta S, Haldar S, Ghosh TK. Comparative efficacy of an organic acid blend and bacitracin methylene disalicylate as growth promoters in broiler chickens: Effects on performance, gut histology, and small intestinal milieu. Veterinary Medicine International. 2010:18.

5. Samli HE, Sirci G, Lorenzo Bermejo J, Koc F, Agma Okur A, Senkoylu N. Effect of addition of a commercial organic acid mixture on feed microbiology according to duration and conditions of storage. Acta Agriculturae Scandinavica A: Animal Sciences. 2008; 58:186-90.

6. Chaveerach P, Keuzenkamp DA, Lipman LJA, Van Knapen F. Effect of Organic Acids in Drinking Water for Young Broilers on Campylobacter Infection, Volatile Fatty Acid Production, Gut Microflora and Histological Cell Changes. Poultry Science. 2004; 83:330-34.

7. Hernández F, García V, Madrid J, Orengo J, Catalá P, Megías MD. Effect of formic acid on performance, digestibility, intestinal histomorphology and plasma metabolite levels of broiler chickens. British Poultry Science. 2006; 47:50-56.

8. Yamauchi K. Review on Chicken Intestinal Villus Histological Alterations Related with Intestinal Function. The Journal of Poultry Science. 2002; 39:229-42.

9. Jansen W, Reich F, Klein G. Large-scale feasibility of organic acids as a permanent preharvest intervention in drinking water of broilers and their effect on foodborne Campylobacter spp. before processing. Journal of Applied Microbiology. 2014; 116:1676-87.

10. Choi PM, Sun RC, Guo J, Erwin CR, Warner BW. High-Fat Diet Enhances Villus Growth During the Adaptation Response to Massive Proximal Small Bowel Resection. Journal of Gastrointestinal Surgery. 2014; 18:286-94.

11. Park JH, Grandjean CJ, Hart MH, Baylor JM, Vanderhoof JA. Effects of Dietary Linoleic Acid on Mucosal Adaptation after Small Bowel Resection. Digestion. 1989; 44:57-65.

12. Sukhotnik I, Lerner A, Sabo E, Krausz MM, Siplovich L, Coran AG, Mogilner J, Shiloni E. Effects of Enteral Arginine Supplementation on the Structural Intestinal Adaptation in a Rat Model of Short Bowel Syndrome. Digestive Diseases and Sciences. 2003; 48:1346-51. 
13. Tappenden KA. Mechanisms of Enteral Nutrient-Enhanced Intestinal Adaptation. Gastroenterology. 2006; 130:S93-99.

14. Bohorquez D V., Bohorquez NE, Ferket PR. Ultrastructural development of the small intestinal mucosa in the embryo and turkey poult: A light and electron microscopy study. Poultry Science. 2011; 90:842-55

15. Fischer ER, Hansen BT, Nair V, Hoyt FH, Dorward DW. Scanning Electron Microscopy. Curr. Protoc. Microbiol., vol. 25, Hoboken, NJ, USA, John Wiley \& Sons, Inc. 2012; 25vol., p. 2B.2.1-2B.2.47.

16. Ding BA, Pirone A, Lenzi C, Xiaoming N, Baglini A, Romboli I. Histochemical features of the Muscovy duck small intestine during development. Tissue and Cell. 2011; 43:190-95.

17. Ruttanavut J, Yamauchi K, Goto H, Erikawa T. Effects of Dietary Bamboo Charcoal Powder Including Vinegar Liquid on Growth Performance and Histological Intestinal Change in Aigamo Ducks. International Journal of Poultry Science. 2009; 8:229-36.

18. Khambualai O, Ruttanavut J, Kitabatake M, Goto H, Erikawa T, Yamauchi K. Effects of dietary natural zeolite including plant extract on growth performance and intestinal histology in Aigamo ducks. British Poultry Science. 2009; 50:123-30.

19. Partanen KH, Mroz Z. Organic acids for performance enhancement in pig diets. Nutrition Research Reviews. 1999; 12:117-45.

20. Noy Y, Sklan D. Digestion and Absor- ption in the Young Chick. Poultry Science. 1995; 74:366-73.

21. Jamroz D, Wiliczkiewicz A, Orda J, Wertelecki T, Skorupinska J. Aspects of development of digestive activity of intestine in young chickens, ducks and geese. Journal of Animal Physiology and Animal Nutrition. 2002; 86:353-66.

22. Yamauchi KE, Isshiki Y. Scanning electron microscopic observations on the intestinal villi in growing white leghorn and broiler chickens from 1 to 30 days of age. British Poultry Science. 1991; 32:67-78.

23. Garcia V, Catala-Gregori P, Hernandez F, Megias MD, Madrid J. Effect of Formic Acid and Plant Extracts on Growth, Nutrient Digestibility, Intestine Mucosa Morphology, and Meat Yield of Broilers. The Journal of Applied Poultry Research. 2007; 16:555-62.

24. Paul SK, Halder G, Mondal MK, Samanta G. Effect of Organic Acid Salt on the Performance and Gut Health of Broiler Chicken. The Journal of Poultry Science. 2007; 44:389-95.

25. Witlock DR, Wyatt RD, Ruff MD. Morphological changes in the avian intestine induced by citrinin and lack of effect of aflatoxin and T-2 toxin as seen with scanning electron microscopy. Toxicon. 1977; 15:41-44.

26. Kadhim KK, Bakar MZA, Noordin MM, Babjee MA, Saad MZ. Light and scanning electron microscopy of the small intestine of young Malaysian village chicken and commercial broiler. Pertanika Journal of Tropical Agricultural Science. 2014; 37:51-64. 